Check for updates

Cite this: RSC Adv., 2019, 9, 22295

\title{
Mechanical and self-recovery properties of supramolecular ionic liquid elastomers based on host-guest interactions and correlation with ionic liquid content $\uparrow$
}

\author{
Garry Sinawang, (D) a Yuichiro Kobayashi, (DD a Motofumi Osaki, (DD a \\ Yoshinori Takashima, (D) *ab Akira Harada (DD *ac and Hiroyasu Yamaguchi (D) *a
}

\begin{abstract}
Supramolecular materials have received considerable attention due to their higher fracture energy and selfrecovery capability compared to conventional chemically cross-linked materials. Herein, we focus on the mechanical properties and self-recovery behaviours of supramolecular polymeric elastomers swollen with ionic liquid. We also gained insight into the correlation between ionic liquid content and mechanical properties. These supramolecular polymers with ionic liquid can be easily prepared from bulk copolymerization of the host-guest complex (peracetylated cyclodextrin and adamantane derivatives) and alkyl acrylates and subsequent immersion in ionic liquid such as 1-ethyl-3-methylimidazolium bis(trifluoromethylsulfonyl)imide. The supramolecular polymeric elastomers showed a self-recovery ability, which the conventional chemically cross-linked elastomers with ionic liquid cannot achieve.
\end{abstract}

Received 20th June 2019

Accepted 10th July 2019

DOI: $10.1039 / c 9 r a 04623 b$

rsc.li/rsc-advances

\section{Introduction}

Supramolecular materials ${ }^{1-3}$ have attracted attention for their characteristic properties. Several types of non-covalent bonds such as hydrogen bonds, ${ }^{4} \pi-\pi$ stacking, ${ }^{5,6}$ electrostatic interactions, ${ }^{7}$ metal-ligand interactions, ${ }^{8,9}$ and hydrophobic interactions $\mathrm{s}^{10}$ have been used to prepare supramolecular materials. Among those non-covalent bonds, host-guest interaction is one of the most fascinating to construct supramolecular materials. They are especially favourable for self-healing materials. ${ }^{11,12}$ Crown ethers, ${ }^{13,14}$ calixarenes, ${ }^{15,16}$ cucurbiturils, ${ }^{17,18}$ pillararenes, ${ }^{19,20}$ and cyclodextrins (CDs) ${ }^{21,22}$ are typical macrocyclic molecules used as host molecules. We prepared supramolecular materials by polymerization of $\mathrm{CD}$ and guest monomers; these materials showed enhanced mechanical properties comparable with covalently cross-linked materials. ${ }^{23}$

Recently, ionic liquids have been used as solvent in polymer network gels because of their characteristic physicochemical

${ }^{a}$ Department of Macromolecular Science, Graduate School of Science, Osaka University, 1-1 Machikaneyama, Toyonaka, Osaka 560-0043, Japan. E-mail: takasima@chem.sci.osaka-u.ac.jp; harada@chem.sci.osaka-u.ac.jp; hiroyasu@chem. sci.osaka-u.ac.jp

${ }^{b}$ Institute for Advanced Co-Creation Studies, Osaka University, 1-1 Yamadaoka, Suita, Osaka 565-0871, Japan

'The Institute of Scientific and Industrial Research, Osaka University, 8-1 Mihogaoka, Ibaraki, Osaka 567-0047, Japan

$\dagger$ Electronic supplementary information (ESI) available: Preparation and characterization of PAc $\gamma \mathrm{CD}$, EMIm TFSI, and elastomers. Strain and stress curve for A-Acrylate- $\boldsymbol{x}$ and B-Acrylate- $\boldsymbol{y}$. See DOI: $10.1039 / \mathrm{c} 9 \mathrm{ra04623b}$ properties, such as negligible volatility, high thermal and electrochemical stability, non-flammability, and great ionic conductivity at room temperature. ${ }^{24-26}$ The use of ionic liquids in polymer networks prevents leakage of the ionic liquids during practical application. ${ }^{27}$ There are several methods to incorporate ionic liquids into the polymer networks, such as polymerizing the monomers, ${ }^{28,29}$ using as polymerization solvents, ${ }^{30-34}$ and swelling the elastomeric films. ${ }^{35-41}$

Several reports of ionic gels based on supramolecular chemistry were reported by using ionic bonds, ${ }^{42,43}$ hydrogen bond, ${ }^{44,45}$ block copolymers, ${ }^{46,47}$ and small gelators. ${ }^{48-50}$ We reported supramolecular materials with self-healing and tough properties, ${ }^{51,52}$ but most of these materials are hydrogels, which are hard to be applied as electrochemical materials because water in the hydrogels possibly causes short circuit. Here, to overcome this problem, we prepared supramolecular hostguest polymeric elastomers swollen with ionic liquid (A-Acrylate- $x$ ). Peracetylated acrylamide-methyl ether-modified $\gamma C D$ host molecules (PAc $\gamma \mathrm{CD}$, Fig. 1a) and 2-ethyl-2-adamanthyl acrylate (Ad) guest molecules were used in the presence of alkyl acrylates to form supramolecular polymeric materials, that is, poly(alkyl acrylate)s tethering the host and guest units as the side chains. 1-Ethyl-3-methylimidazolium bis(trifluoromethylsulfonyl)imide (EMIm TFSI) was used as ionic liquid for swelling the supramolecular polymeric materials (Fig. 1b).

Previously, we discussed about the relation between hostguest cross-linking and the ionic conductivity in supramolecular elastomers swollen by ionic liquid (IEs).$^{53}$ Herein, we focus on the mechanical properties and self-recovery behaviour of 
(a) Chemical structure of peracetylated $\mathrm{CCD}$ monomer

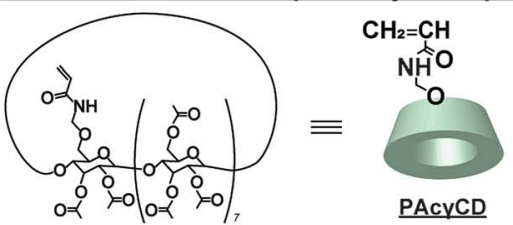

(b) Chemical structure of EMIm TFSI as an ionic liquid

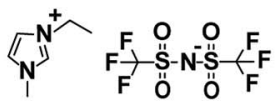

(c) Chemical structures of ionic liquid elastomers (IE)

Supramolecular IE [A-Acrylate-x]

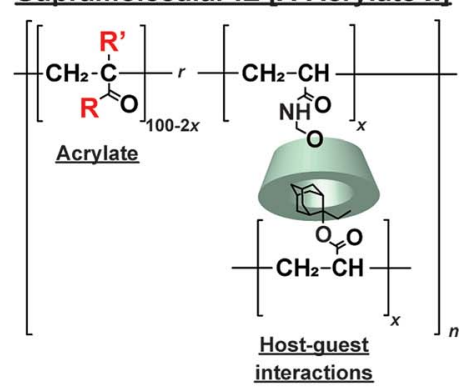

Chemically cross-linked IE [B-Acrylate-y]

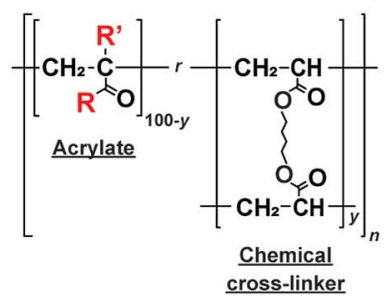

(d) Chemical structures of acrylate (Acrylate)

\begin{tabular}{|c|c|c|c|}
\hline Methyl acrylate & (1) & $: R:$ 人o' & $\mathbf{R}^{\prime}:$ 人 \\
\hline Ethyl acrylate & (2) & $: R:$ ROA & $\mathbf{R}^{\prime}: \Lambda_{H}$ \\
\hline Butyl acrylate & (3) & $: R:$ 人 & $\mathrm{R}^{\prime}$ : 人 $\mathrm{H}$ \\
\hline Methyl methacrylate & (4) & $: \mathrm{R}: /$ & $\mathrm{CH}_{3}$ \\
\hline
\end{tabular}

Fig. 1 Chemical structures of (a) peracetylated 6-acrylamido methylether- $\gamma C D$ monomer (PAC $\gamma C D$ ) as the host monomer, (b) 1-ethyl-3methylimidazolium bis(trifluoromethylsulfonyl) imide (EMIm TFSI) as an ionic liquid, and (c) supramolecular polymeric elastomer swollen with EMIm TFSI (A-Acrylate- $x$ ) and chemically cross-linked elastomer swollen with EMIm TFSI (B-Acrylate-y). (d) Group of side chain monomers (acrylate): methyl acrylate (1), ethyl acrylate (2), butyl acrylate (3), and methyl methacrylate (4). $x$ and $y$ respectively indicate the mol\% content of cross-linking unit of the host-guest inclusion complex (PAcrCD and Ad) and BDA units.

supramolecular IEs. We investigated the mechanical properties of these supramolecular IEs with several types of alkyl acrylate side chain polymers (Fig. 1c and d). The A-Acrylate- $\boldsymbol{x}$ showed a lower Young's modulus but a higher fracture energy than chemically cross-linked IEs. The A-Acrylate- $\boldsymbol{x}$ also showed selfrecovery properties which cannot be achieved by chemically cross-linked IEs. These self-recovery properties also are a new finding in polymeric ionic liquid materials.

\section{Experimental section}

\subsection{Materials}

Methyl acrylate (1), ethyl acrylate (2), n-butyl acrylate (3), and methyl methacrylate (4) were purchased from Toagosei Co., Ltd. $\gamma$-Cyclodextrin $(\gamma \mathrm{CD})$ was obtained from Junsei Chemical Co. Ltd. 1-Hydroxy cyclohexyl phenyl ketone (Ciba, IRGACURE 184) was purchased from BASF Japan Co., Ltd. 2-Ethyl-2-adamantyl acrylate (Ad) was obtained from Osaka Organic Chemical Industry Ltd. 1,4-Butanediol diacrylate (BDA), acetic anhydride, and bromoethane were purchased from Nacalai Tesque Inc. Lithium bis(trifluoromethanesulfonyl)imide (LiTFSI) was purchased from Tokyo Chemical Industry Co., Ltd. PAc $\gamma$ CD was prepared according to Scheme S1 in ESI (Fig. S1-S3†). EMIm TFSI was prepared according to Scheme S2 and S3 in ESI (Fig. S4-S8†). Pyridine and $\mathrm{CDCl}_{3}$ were purchased from Wako Pure Chemical Industries, Ltd. DMSO- $d_{6}$ was obtained from Merck \& Co., Inc. Water used for the preparation of the aqueous solutions was purified with a Millipore Elix 5 system. Other reagents were used without further purification.

\subsection{Characterization}

${ }^{1} \mathrm{H},{ }^{13} \mathrm{C}$, and ${ }^{19} \mathrm{~F}$ nuclear magnetic resonance (NMR) spectra were recorded at $500 \mathrm{MHz}\left(\right.$ for ${ }^{1} \mathrm{H}$ ), $125 \mathrm{MHz}$ (for ${ }^{13} \mathrm{C}$ ), and 470 $\mathrm{MHz}$ (for ${ }^{19} \mathrm{~F}$ ), with a JEOL JNM-ECA 500 spectrometer at $25{ }^{\circ} \mathrm{C}$. ${ }^{19} \mathrm{~F}$ NMR spectra were calibrated using the external standard $\mathrm{CFCl}_{3}(\delta=0 \mathrm{ppm})$. Solid-state ${ }^{1} \mathrm{H}$ field gradient magic angle spinning (FGMAS) NMR spectra was recorded at $400 \mathrm{MHz}$ with a JEOL JNM-ECA 400 NMR spectrometer with a sample spinning rate of $7 \mathrm{kHz}$. In all the solid-state NMR measurements, the chemical shifts were referenced to residual protons values of the deuterated solvent $\left[{ }^{1} \mathrm{H}\right.$ NMR: $\delta=0$ ppm for tetramethylsilane (TMS) and $2.49 \mathrm{ppm}$ for DMSO- $d_{6} ;{ }^{13} \mathrm{C}$ NMR: $\delta=0 \mathrm{ppm}$ for TMS and 39.52 ppm for DMSO- $d_{6}$ ]. Positive-ion matrix-assisted laser desorption/ionization time-of-flight mass spectrometry (MALDI-TOF MS) experiments were performed using a Bruker autoflex speed mass spectrometer using 2,5-dihydroxybenzoic acid as matrix. The mass number was calibrated by four peptides, i.e., angiotensin II $\left([\mathrm{M}+\mathrm{H}]^{+}\right.$1046.5418), angiotensin I $\left([\mathrm{M}+\mathrm{H}]^{+} 1296.6848\right)$, substance $\mathrm{P}\left([\mathrm{M}+\mathrm{H}]^{+} 1347.7354\right)$, and bombesin $\left([\mathrm{M}+\mathrm{H}]^{+} 1619.8223\right)$. The mechanical properties of the IEs were measured using Autograph AG-X plus (Shimadzu Co.) equipped with a $50 \mathrm{~N}$ load cell at a specific deformation rate $\left(1.0 \mathrm{~mm} \mathrm{~s}^{-1}\right)$. The conductivity of the IEs was measured by a Hewlett-Packard 4284A Precision LCR (inductance $(L)$, capacitance $(C)$, and resistance $(R))$ metre at a frequency of $20 \mathrm{~Hz}$ to $1 \mathrm{MHz}$ using a stainless-steel electrode with a sample diameter of $20 \mathrm{~mm}$.

\section{Results and discussion}

3.1. Preparation of the supramolecular ionic liquid elastomer

The supramolecular polymeric IEs based on CD with guest unit (A-Acrylate- $\boldsymbol{x}$ ) were prepared according to our previous report (Scheme $\mathrm{S} 4 \dagger) .{ }^{53}$ Ad as a guest monomer and PAc $\gamma \mathrm{CD}$ as a host 
monomer were mixed and sonicated in an alkyl acrylate monomer to form inclusion complex. Then, bulk radical copolymerization was carried out by using IRGACURE 184 with irradiation of $365 \mathrm{~nm}$ UV to produce the supramolecular elastomer. The resulting elastomer was readily immersed in the EMIm TFSI to obtain the supramolecular elastomer swollen with EMIm TFSI, A-Acrylate- $\boldsymbol{x}$ (Table S9†). As control samples, chemically cross-linked IEs (B-Acrylate-y, Fig. 1c and Table $\mathrm{S} 10^{\dagger}$ ), were prepared by the same manner.

The composition ratio in the IEs is indicated by $x$ and $y$ in AAcrylate- $\boldsymbol{x}$ and B-Acrylate- $\boldsymbol{y}$, which respectively represent the mol\% content of cross-linking unit of the host-guest inclusion complex (PAc $\gamma \mathrm{CD}$ and Ad) or BDA. Solid-state ${ }^{1} \mathrm{H}$ FGMAS NMR measurements were carried out to determine the amount of PAc $\gamma \mathrm{CD}$ and Ad unit in A-Acrylate- $\boldsymbol{x}$ elastomer and AAcrylate- $\boldsymbol{x}$. These amounts coincided with the predefined ratio of the corresponding monomers, indicating that the copolymerization proceeded, quantitatively (Fig. S9-S16†).

\subsection{Mechanical properties of the ionic liquid elastomers}

The mechanical properties of the A-Acrylate- $\boldsymbol{x}$ were investigated via universal tensile strength test, and the results were compared with the B-Acrylate- $\boldsymbol{y}$. The stress and strain curves of the A-Acrylate- $\boldsymbol{x}$ and B-Acrylate-y (Fig. S17-S20†) were evaluated while stretching at a tensile speed of $1.0 \mathrm{~mm} \mathrm{~s}^{-1}$. Then, the Young's modulus and fracture energy were calculated from the stress-strain curve (Table 1, Fig. S21 and S22 $\dagger$ ).

Table 1 shows mechanical properties (ultimate strength, Young's modulus, and fracture energy) of the A-Acrylate-1 and B-Acrylate-1. First, we investigated the relationship between ultimate strength and Young's modulus. Different acrylate groups also showed different ultimate strengths and Young's modulus results. The A-4-1 showed Young's modulus (34 MPa) and ultimate strength $(8 \mathrm{MPa})$ which almost comparable with the chemically cross-linked B-4-1 (Young's modulus: $66 \mathrm{MPa}$ and ultimate strength: $8 \mathrm{MPa}$ ).

Another acrylate groups (A-2-1) tended to be more elastic with lower Young's modulus: $0.01 \mathrm{MPa}$ and ultimate strength: 0.1 MPa compared to the chemically cross-linked B-2-1 (Young's modulus: $0.81 \mathrm{MPa}$ and ultimate strength: $0.18 \mathrm{MPa}$ ). These results are caused by the apparent lower cross-linking density in the A-Acrylate- $\boldsymbol{x}$, because the cross-linking points by the CD and Ad units can associate and dissociate freely.

The relationship between the fracture energy and Young's modulus for the A-Acrylate-1 and B-Acrylate-1 also investigated. The A-4-1 showed Young's modulus and fracture energy values comparable with the chemically cross-linked B-4-1. As for fracture energy, the A-3-1 showed a higher fracture energy (3200 kJ $\left.\mathrm{m}^{-2}\right)$ compared to the chemically cross-linked B-3-1 $\left(43 \mathrm{~kJ} \mathrm{~m}^{-2}\right)$, however they showed lower Young's modulus. Same trends were observed in the A-1-1 and A-2-1. These results showed that the host-guest interactions in the A-Acrylate- $\boldsymbol{x}$ is important to increase the fracture energy of the IEs.
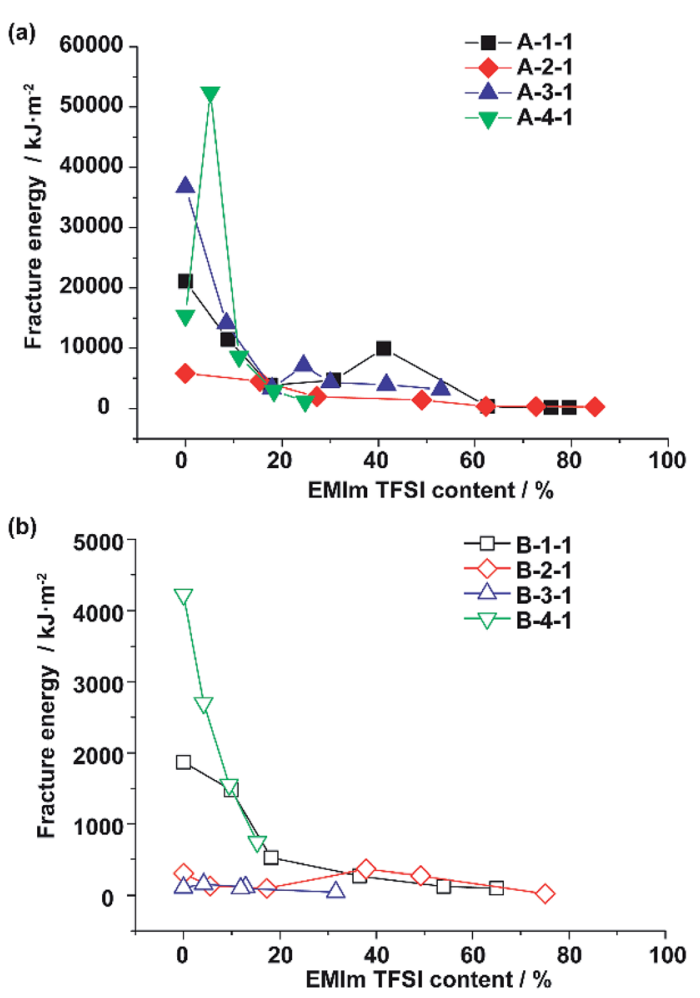

Fig. 2 Relationship between the fracture energy and ionic liquid (EMIm TFSI) content for (a) supramolecular ionic liquid elastomer (AAcrylate-1) and (b) chemically cross-linked ionic liquid elastomer (BAcrylate-1). [ $\mathbf{\square}$ : Methyl acrylate (1), $\bullet$ : ethyl acrylate (2), $\mathbf{\Delta}$ : butyl acrylate (3), and $\mathbf{\nabla}$ : methyl methacrylate (4)].

Table 1 Mechanical properties of supramolecular ionic liquid elastomer (A-Acrylate-1) and chemically cross-linked elastomer (B-Acrylate-1). Acrylate: methyl acrylate (1), ethyl acrylate (2), butyl acrylate (3), and methyl methacrylate (4)

\begin{tabular}{llcl}
\hline Chemical structures & Strength/MPa & $\begin{array}{l}\text { Young's } \\
\text { modulus/MPa }\end{array}$ & $\begin{array}{l}\text { Fracture energy/kJ } \\
\mathrm{m}^{-2}\end{array}$ \\
\hline A-1-1 & 0.060 & 0.08 & 180 \\
A-2-1 & 0.10 & 0.01 & 310 \\
A-3-1 & 0.50 & 0.01 & 3200 \\
A-4-1 & 8.0 & 34 & 870 \\
B-1-1 & 0.40 & 1.4 & 98 \\
B-2-1 & 0.20 & 0.80 & 22 \\
B-3-1 & 0.20 & 0.90 & 43 \\
B-4-1 & 8.0 & 66 & 750
\end{tabular}


Interestingly, the EMIm TFSI content also takes part in the fracture energy. Fig. 2a shows the relationship between the fracture energy and EMIm TFSI content (wt\%) for A-Acrylate- $\boldsymbol{x}$, and Fig. $2 \mathrm{~b}$ shows those for B-Acrylate-y. The higher ionic liquid content often lowered the mechanical property values, but at a certain point around $20-60 \%$, local maxima of the fracture energy were observed. Comparison between Fig. 2a and b also shows that in every EMIm TFSI content, A-Acrylate- $\boldsymbol{x}$ shows higher fracture energy than B-Acrylate-y.

The A-4-1 showed a local peak of the fracture energy at a 5\% ionic liquid content. Additionally, whereas the fracture energy of A-1-1 and A-3-1 also decreased during the addition of ionic liquid content, the fracture energy increased again to show peaks at a $41 \%$ and a $24 \%$ ionic liquid content, respectively. These results indicate that the host-guest interactions act as noncovalent cross-linkers that associate and dissociate depending on the amounts of EMIm TFSI.

\subsection{Stress relaxation behaviour of the ionic liquid elastomers}

The behaviour of the CD/Ad host-guest interactions in the IEs was observed using stress relaxation tests for both A-Acrylate- $\boldsymbol{x}$ and B-Acrylate- $\boldsymbol{y}$. In the stress relaxation test, the IEs were stretched using a universal tensile test machine to a $5 \%$ strain and observe the stress relaxation with keeping the strain (5\%) for 1 hour. All stress values recorded during the tests were plotted as normalized stress values, in which the initial stresses are normalized as 1 (Fig. 3a).

The stress relaxation time constants $(\tau)$ were calculated from the curve fitting of the stress relaxation curve profile for exponential decreasing model (ESI section 9†). The A-Acrylate- $\boldsymbol{x}$ showed two relaxation modes. On the other hand, B-Acrylate-y showed single relaxation mode.

Fig. 3b summarizes the $\tau$ values. The $\tau$ of the slow relaxation mode of A-Acrylate- $\boldsymbol{x}$ (A-1-1: $120 \mathrm{~s}, \mathbf{A - 2 - 1 :} 160 \mathrm{~s}, \mathbf{A - 3 - 1 :} 180 \mathrm{~s}$, and A-4-1: $170 \mathrm{~s}$ ) were approximately one order higher than those of the chemically cross-linked B-Acrylate-y (B-1-1: $9.2 \mathrm{~s}, \mathbf{B}-\mathbf{2 - 1}: 17 \mathrm{~s}$, B-3-1: $62 \mathrm{~s}$, and B-4-1: $38 \mathrm{~s}$ ). These results suggested the presence of slower molecular motions for the A-Acrylate- $\boldsymbol{x}$ due to host-guest interactions. The $\tau$ values indicated that A-Acrylate-1 with a smaller size of side chain, such as A-1-1 and A-2-1 showed faster stress relaxation compared to longer size of side chain like A-3-1 and bulky size of side chain like A-4-1, respectively.

As for the other rapid relaxation mode of A-Acrylate- $\boldsymbol{x}$ (shown as $\tau^{\prime}$ in Fig. S23 $\dagger$ ), the short $\tau^{\prime}$ of the A-Acrylate- $\boldsymbol{x}$ supposed to be achieved by the fast association and dissociation of host-guest interactions between PAc $\gamma \mathrm{CD}$ and Ad in the elastomer, which should contribute to the effective stress dispersion mechanism of the A-Acrylate- $\boldsymbol{x}$.

\subsection{Correlation between EMIm TFSI content and ionic conductivity of the ionic liquid elastomers}

One of the most significant point in utilizing an ionic liquid is that these materials show ionic conductivity properties. The ionic conductivity $(\sigma)$ was measured using a computercontrolled Hewlett-Packard 4284 Precision LCR metre with (a)

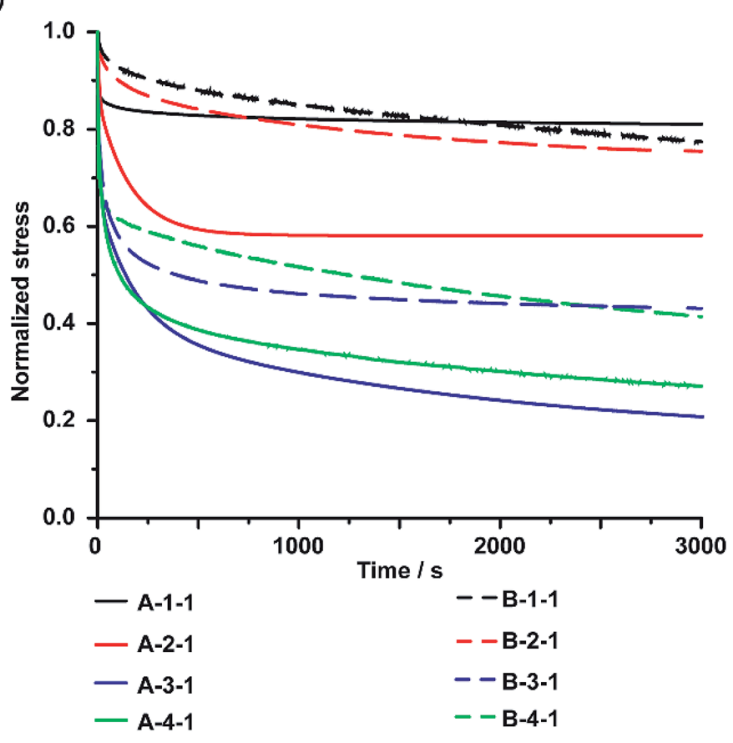

(b)

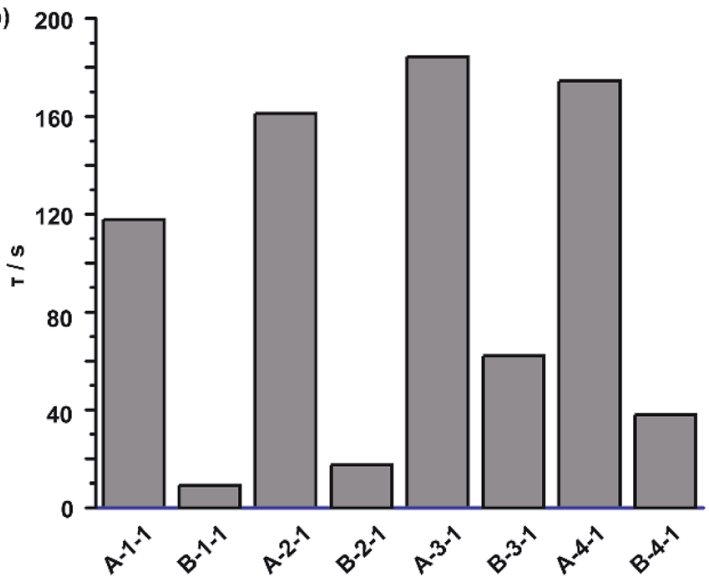

Fig. 3 (a) Stress relaxation behaviour of the supramolecular ionic liquid elastomer (A-Acrylate-1, solid lines) and chemically cross-linked ionic liquid elastomer (B-Acrylate-1, dashed lines) with a 5\% strain for 1 hour. (b) Slow relaxation time constant of the A-Acrylate-1 and BAcrylate-1. Acrylate: methyl acrylate (1), ethyl acrylate (2), butyl acrylate (3), and methyl methacrylate (4).

a frequency range of $20 \mathrm{~Hz}$ to $1 \mathrm{MHz}$ at a temperature of $25^{\circ} \mathrm{C}$, and then $\sigma$ was calculated using Jonscher's Universal Power $\operatorname{Law}^{\mathbf{5 4 , 5 5}}$ (Fig. S24 $\dagger$ ). The $\sigma$ of EMIm TFSI as a native ionic liquid, the A-Acrylate- $\boldsymbol{x}$, and the B-Acrylate- $\boldsymbol{y}$ are shown at Fig. S25. $\dagger$ Herein, we focus on the dependency of EMIm TFSI content on the $\sigma$ in the A-Acrylate-1 (Fig. 4). We found that there was a critical point, approximately $60 \%$ of the EMIm TFSI content, where the $\sigma$ value drastically increased. This drastic increase only occur in supramolecular polymeric IEs but chemically cross-linked IEs did not show significant increase of $\sigma$. Some chemically cross-linked IEs cannot even contain EMIm TFSI at high content $(<60 \%)$. EMIm TFSI could percolate through the A1-1 and A-2-1 with a maximum content of over $60 \%$, which makes A-1-1 and A-2-1 show high $\sigma$ values, whereas the A-3-1 and A-4-1 only contained maximum of $53 \%$ and $25 \%$ of EMIm, 


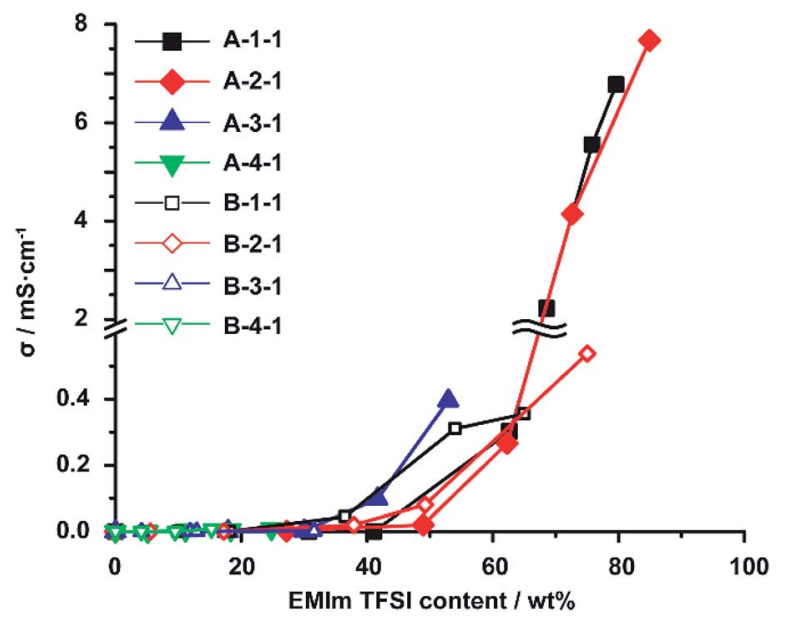

Fig. 4 Relationship between the ionic conductivity $(\sigma)$ and ionic liquid (EMIm TFSI) content for supramolecular ionic liquid elastomer (AAcrylate-1) and chemically cross-linked ionic liquid elastomer (BAcrylate-1). [ $\mathbf{\square}$ : Methyl acrylate (1), \&: ethyl acrylate (2), $\mathbf{\Delta}$ : butyl acrylate (3), and $\nabla$ : methyl methacrylate (4)].

respectively. Therefore, the A-3-1 and A-4-1 showed lower $\sigma$ values.

Fig. 4 also shows that at 65\% EMIm TFSI content, A-1-1 $(\sigma=$ $\left.2.1 \mathrm{mS} \mathrm{cm}^{-1}\right)$ showed higher $\sigma$ than B-1-1 $\left(\sigma=0.40 \mathrm{mS} \mathrm{cm}^{-1}\right)$ and also for around 75\% EMIm TFSI content A-2-1 $(\sigma=4.1$ $\left.\mathrm{mS} \mathrm{cm}{ }^{-1}\right)$ showed higher $\sigma$ than B-2-1 $\left(\sigma=0.50 \mathrm{mS} \mathrm{cm}^{-1}\right)$. This result proved that A-1-1 and A-2-1 showed higher $\sigma$ compared to chemically cross-linked B-1-1 and B-2-1 even in the same EMIm TFSI content. This phenomena is caused by reversible and elastic cross-linker in supramolecular polymeric IE makes mobility of substituents of EMIm TFSI are faster compared to mobility of substituents of EMIm TFSI inside the chemically cross-linked IE.

\subsection{Self-recovery properties of supramolecular ionic liquid elastomers}

Host-guest interactions are popular for their capability as selfrecovery material. We also investigated the self-recovery of the A-Acrylate-1. Fig. 5a shows the test procedure for the selfrecovery properties. Calculation of recovery ratio (see in Fig. S26 and S27 in ESI $\dagger$ ) showed the results obtained from test procedure for the self-recovery properties. The etching method of the self-recovery test was performed using a protocol from our previous report. ${ }^{56}$ For the first cycle, the A-Acrylate-1 was stretched into half of the plastic deformable region and then rested to the initial state. The A-Acrylate-1 was placed either at room temperature or $80{ }^{\circ} \mathrm{C}$ to investigate the temperature dependency on the self-recovery. After 12 hours, for the second cycle, the A-Acrylate-1 was stretched again with the same strain value as the first cycle.

Fig. 5b shows the recovery ratio of the A-Acrylate-1 after two cycles at room temperature (RT) or $80{ }^{\circ} \mathrm{C}$. The A-1-1 and A-2-1 showed full recovery results (100\% and 99\%, respectively) after 12 hours at room temperature and at $80{ }^{\circ} \mathrm{C}$, but the A-3-1 and A4-1 were almost fully recovered ( $98 \%$ and $80 \%$, respectively) only at $80{ }^{\circ} \mathrm{C}$. These results show that A-1-1 and A-2-1 with smaller size of the side chain acrylate show faster stress relaxation compared to B-3-1 and B-4-1, respectively. This phenomena is caused by longer size of side chain like BA and bulky size of side chain like MMA make the inclusion complex of PAc $\gamma \mathrm{CD}$ and Ad units harder to re-join again after dissociation.

A-1-1 showed more than 100\% recovery ratio after placed at $80{ }^{\circ} \mathrm{C}$, because methyl acrylate is the smallest size of side chain which made self-recovery easier than bigger side chain. This

(a) Procedure

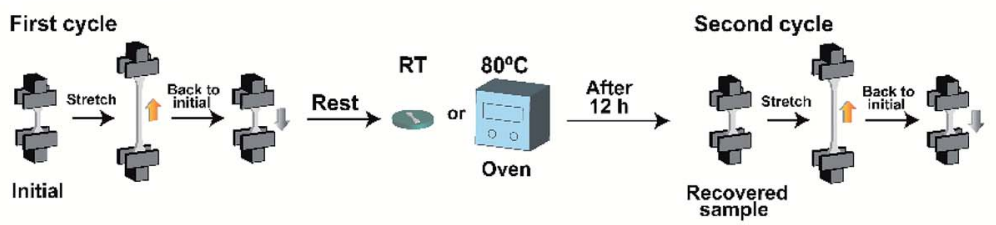

(b) Recovery ratio

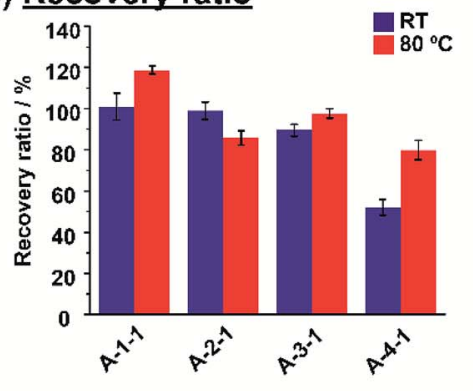

(c) Mechanism of recovery ratio

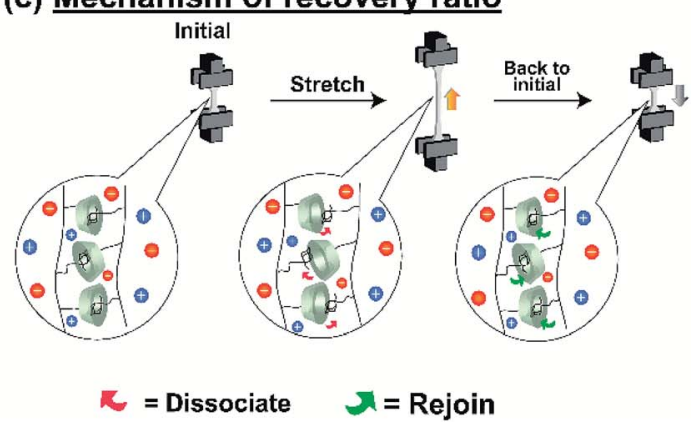

Fig. 5 (a) Procedure for the self-recovery calculation. (b) Recovery ratio for supramolecular ionic liquid elastomer (A-Acrylate-1) after $12 \mathrm{~h}$ at room temperature (blue coloured bar) and $80{ }^{\circ} \mathrm{C}$ (red coloured bar). (c) Schematic illustration of the self-recovery mechanism. Acrylate: methyl acrylate (1), ethyl acrylate (2), butyl acrylate (3), and methyl methacrylate (4). 
result was also supported by Young's modulus of A-1-1 during self-recovery test (Fig. S28 $\dagger$ ). After first cycle, A-1-1 showed Young's modulus of $0.07 \mathrm{MPa}$. For the same sample rested in RT, it showed similar Young's modulus. But, for the sample rested at $80{ }^{\circ} \mathrm{C}$, it showed higher Young's modulus (0.08 MPa) than in the first cycle. These results confirmed that the AAcrylate-1 shows self-recovery properties.

Fig. 5c illustrates the schematic mechanism of the selfrecovery. While the A-Acrylate-1 materials were stretched, several host-guest interactions dissociated. This behaviour contributes to the stress dispersion of the material, resulting in the high fracture energy. During a rest period, those host and guest units re-joined through host-guest interactions to recover the cross-linking again. Thus, the material returned to its original state to show the self-recovery.

\section{Conclusions}

Supramolecular polymeric IEs were successfully prepared from the bulk copolymerization of host-guest elastomer containing PAc $\gamma$ CD and Ad with immersion in EMIm TFSI. The Young's moduli of the A-Acrylate- $\boldsymbol{x}$ were lower than those of the chemically cross-linked IEs, indicating that the A-Acrylate- $\boldsymbol{x}$ have a flexible cross-linking points. Although low Young's modulus materials are generally soft and brittle with showing low fracture energy, however the fracture energy of the A-Acrylate- $\boldsymbol{x}$ with a low Young's modulus is higher than that of the chemically cross-linked IEs. We concluded that host-guest interactions are an important part of the supramolecular polymeric IEs for preparing flexibly cross-linked materials with a high fracture energy, and these materials can also be self-recovered. A-1-1 and A-2-1 show full recovery results after 12 hours at room temperature and at $80{ }^{\circ} \mathrm{C}$. In the near future, supramolecular polymeric IEs based on host-guest interactions are promising for applications in electrochemical materials.

\section{Conflicts of interest}

There are no conflicts to declare.

\section{Acknowledgements}

This research was funded by a Grant-in-Aid for Scientific Research (B) (18H02035, 17H03115, 17H03416, and MJMI18E3) from the MEXT of Japan, the Mazda Foundation, and Research Grant Program of the Asahi Glass Foundation (2015 and 2018). We wish to thank Prof. T. Inoue and Dr O. Urakawa of Osaka University for access to the conductivity measurements. We also wish to acknowledge the technical assistance of Dr N. Inazumi for the NMR measurements.

\section{References}

1 L. Brunsveld, B. J. B. Folmer, E. W. Meijer and R. P. Sijbesma, Chem. Rev., 2001, 101, 4071-4098.

2 A. Harada, Supramolecular Polymer Chemistry, Wiley-VCH Verlag \& Co. KGaA, Weinheim, 2012.
3 J.-M. Lehn, Polym. Int., 2002, 51, 825-839.

4 P. Cordier, F. Tournilhac, C. Soulié-Ziakovic and L. Leibler, Nature, 2008, 451, 977.

5 S. Burattini, H. M. Colquhoun, J. D. Fox, D. Friedmann, B. W. Greenland, P. J. F. Harris, W. Hayes, M. E. Mackay and S. J. Rowan, Chem. Commun., 2009, 6717-6719.

6 J. Fox, J. J. Wie, B. W. Greenland, S. Burattini, W. Hayes, H. M. Colquhoun, M. E. Mackay and S. J. Rowan, J. Am. Chem. Soc., 2012, 134, 5362-5368.

7 Q. Wang, J. L. Mynar, M. Yoshida, E. Lee, M. Lee, K. Okuro, K. Kinbara and T. Aida, Nature, 2010, 463, 339.

8 M. Burnworth, L. Tang, J. R. Kumpfer, A. J. Duncan, F. L. Beyer, G. L. Fiore, S. J. Rowan and C. Weder, Nature, 2011, 472, 334.

9 R. J. Wojtecki, M. A. Meador and S. J. Rowan, Nat. Mater., 2010, 10, 14 .

10 D. C. Tuncaboylu, M. Sari, W. Oppermann and O. Okay, Macromolecules, 2011, 44, 4997-5005.

11 X. Chen, M. A. Dam, K. Ono, A. Mal, H. Shen, S. R. Nutt, K. Sheran and F. Wudl, Science, 2002, 295, 1698.

12 N. Roy, B. Bruchmann and J.-M. Lehn, Chem. Soc. Rev., 2015, 44, 3786-3807.

13 C. J. Pedersen, J. Am. Chem. Soc., 1967, 89, 7017-7036.

14 C. J. Pedersen, J. Am. Chem. Soc., 1967, 89, 2495-2496.

15 C. D. Gutsche, B. Dhawan, K. H. No and R. Muthukrishnan, J. Am. Chem. Soc., 1981, 103, 3782-3792.

16 X. Yan, F. Wang, B. Zheng and F. Huang, Chem. Soc. Rev., 2012, 41, 6042-6065.

17 W. A. Freeman, W. L. Mock and N. Y. Shih, J. Am. Chem. Soc., 1981, 103, 7367-7368.

18 J. Kim, I.-S. Jung, S.-Y. Kim, E. Lee, J.-K. Kang, S. Sakamoto, K. Yamaguchi and K. Kim, J. Am. Chem. Soc., 2000, 122, 540541.

19 T. Ogoshi, T.-a. Yamagishi and Y. Nakamoto, Chem. Rev., 2016, 116, 7937-8002.

20 M. Xue, Y. Yang, X. Chi, Z. Zhang and F. Huang, Acc. Chem. Res., 2012, 45, 1294-1308.

21 K. Kato, Y. Okabe, Y. Okazumi and K. Ito, Chem. Commun., 2015, 51, 16180-16183.

22 C. Koopmans and H. Ritter, Macromolecules, 2008, 41, 74187422.

23 A. Harada, Y. Takashima and M. Nakahata, Acc. Chem. Res., 2014, 47, 2128-2140.

24 M. Armand, F. Endres, D. R. MacFarlane, H. Ohno and B. Scrosati, Nat. Mater., 2009, 8, 621-629.

25 R. D. Rogers and K. R. Seddon, Science, 2003, 302, 792-793. 26 T. Welton, Chem. Rev., 1999, 99, 2071-2083.

27 A. Wu, F. Lu, P. Sun, X. Qiao, X. Gao and L. Zheng, Langmuir, 2017, 33, 13982-13989.

28 H. Ohno and K. Ito, Chem. Lett., 1998, 27, 751-752.

29 J. Y. Yuan and M. Antonietti, Polymer, 2011, 52, 1469-1482.

30 A. J. Carmichael, D. M. Haddleton, S. A. F. Bon and K. R. Seddon, Chem. Commun., 2000, 1237-1238.

31 S. Harrisson, S. R. Mackenzie and D. M. Haddleton, Chem. Commun., 2002, 2850-2851.

32 S. Harrisson, S. R. Mackenzie and D. M. Haddleton, Macromolecules, 2003, 36, 5072-5075. 
33 J. L. Kaar, A. M. Jesionowski, J. A. Berberich, R. Moulton and A. J. Russell, J. Am. Chem. Soc., 2003, 125, 4125-4131.

34 A. Noda and M. Watanabe, Electrochim. Acta, 2000, 45, 12651270.

35 K. Fujii, H. Asai, T. Ueki, T. Sakai, S. Imaizumi, U.-i. Chung, M. Watanabe and M. Shibayama, Soft Matter, 2012, 8, 17561759.

36 J. M. Harner and D. A. Hoagland, J. Phys. Chem. B, 2010, 114, 3411-3418.

37 J. C. Jansen, K. Friess, G. Clarizia, J. Schauer and P. Izák, Macromolecules, 2011, 44, 39-45.

38 M. A. Klingshirn, S. K. Spear, R. Subramanian, J. D. Holbrey, J. G. Huddleston and R. D. Rogers, Chem. Mater., 2004, 16, 3091-3097.

39 K. Matsumoto and T. Endo, Macromolecules, 2008, 41, 69816986.

40 S. Seki, A. B. H. Susan, T. Kaneko, H. Tokuda, A. Noda and M. Watanabe, J. Phys. Chem. B, 2005, 109, 3886-3892.

41 M. A. Susan, T. Kaneko, A. Noda and M. Watanabe, J. Am. Chem. Soc., 2005, 127, 4976-4983.

42 X. Li, H. Charaya, G. M. Bernard, J. A. W. Elliott, V. K. Michaelis, B. Lee and H.-J. Chung, Macromolecules, 2018, 51, 2723-2731.

43 T. L. Sun, T. Kurokawa, S. Kuroda, A. B. Ihsan, T. Akasaki, K. Sato, M. A. Haque, T. Nakajima and J. P. Gong, Nat. Mater., 2013, 12, 932.

44 A. Noro, Y. Matsushita and T. P. Lodge, Macromolecules, 2009, 42, 5802-5810.
45 Y. J. Kim, J. H. Kim, M. S. Kang, M. J. Lee, J. Won, J. C. Lee and Y. S. Kang, Adv. Mater., 2004, 16, 1753-1757.

46 D. F. Miranda, C. Versek, M. T. Tuominen, T. P. Russell and J. J. Watkins, Macromolecules, 2013, 46, 9313-9323.

47 S. P. Zhang, K. H. Lee, C. D. Frisbie and T. P. Lodge, Macromolecules, 2011, 44, 940-949.

48 S. Chen, N. Zhang, B. Zhang, B. Zhang and J. Song, ACS Appl. Mater. Interfaces, 2018, 10, 44706-44715.

49 N. Mohmeyer, D. Kuang, P. Wang, H.-W. Schmidt, S. M. Zakeeruddin and M. Grätzel, J. Mater. Chem., 2006, 16, 2978-2983.

50 W. Zhang, C. Yuan, J. N. Guo, L. H. Qiu and F. Yan, ACS Appl. Mater. Interfaces, 2014, 6, 8723-8728.

51 M. Nakahata, Y. Takashima and A. Harada, Macromol. Rapid Commun., 2016, 37, 86-92.

52 T. Kakuta, Y. Takashima, M. Nakahata, M. Otsubo, H. Yamaguchi and A. Harada, Adv. Mater., 2013, 25, 28492853.

53 G. Sinawang, Y. Kobayashi, Y. Zheng, Y. Takashima, A. Harada and H. Yamaguchi, Macromolecules, 2019, 52, 2932-2938.

54 M. Greenhoe Brian, K. Hassan Mohammad, S. Wiggins Jeffrey and A. Mauritz Kenneth, J. Polym. Sci., Part B: Polym. Phys., 2016, 54, 1918-1923.

55 A. K. Jonscher, Nature, 1977, 267, 673.

56 T. Kakuta, Y. Takashima and A. Harada, Macromolecules, 2013, 46, 4575-4579. 